\title{
NEW GROUP DECISION-MAKING ARCAS APPROACH BASED ON THE INTEGRATION OF THE SWARA AND THE ARAS METHODS ADAPTED FOR NEGOTIATIONS
}

\author{
Dragisa STANUJKIC ${ }^{1}$, Edmundas Kazimieras ZAVADSKAS ${ }^{2}$, \\ Darjan KARABASEVIC ${ }^{3}$, Zenonas TURSKIS ${ }^{4}$, Violeta KERŠULIENÉ ${ }^{5}$
}

${ }^{1}$ Faculty of Management in Zajecar, Jonh Naisbitt University, Park Suma Kraljevica bb, 19000 Zajecar, Serbia

${ }^{2,4}$ Research Institute of Smart Building Technologies, Vilnius Gediminas Technical University, Sauletekio al. 11, 10223 Vilnius, Lithuania

${ }^{3}$ Faculty of Applied Management, Economics and Finance, University Business Academy in Novi Sad, Jevrejska 24, 11000 Belgrade

${ }^{5}$ Department of Law, Faculty of Business Management,

Vilnius Gediminas Technical University, Sauletekio al. 11, 10223 Vilnius, Lithuania

E-mails: ${ }^{1}$ dragisa.stanujkic@fmz.edu.rs, ${ }^{2}$ edmundas.zavadskas@vgtu.lt (corresponding author);

3darjankarabasevic@gmail.com; ${ }^{4}$ zenonas.turskis@vgtu.lt; 5 violeta.kersuliene@vgtu.lt

Received 18 January 2017; accepted 03 May 2017

\begin{abstract}
Groups are generally considered to be more effective as compared to single individuals. The practical implementation of Operation Research methods in group negotiations needs simple contexts and clear cause-and-effect relationships easily discernible by everyone. This paper proposes a multi-criteria group decision-making approach allowing decision makers/experts involved in a negotiation process to better express and defend their preferences in the selection of the best alternative. In the proposed approach, the most appropriate alternative is the alternative with the largest number of appearances in the first position or in ranking lists, or the one determined based on negotiations of decision makers/experts. The proposed ARCAS approach is based on the use of the ARAS method, a new normalization procedure, and the SWARA method. In the proposed approach, each decision maker/expert involved in evaluation has an opportunity to set the preferred level of rating for each criterion used in such evaluation. Finally, a case study is presented in order to highlight the proposed approach. The obtained results confirm the usability and efficiency of the proposed approach.
\end{abstract}

Keywords: group decision-making, negotiation, MCDM, ARAS, SWARA, ARCAS.

JEL Classification: J01, J24, M41, M54, C44.

\section{Introduction}

Compromise, negotiation and group decision theories have considerably developed in the 1970s and the 1980s (Munier, Shakun 1988). Raiffa et al. (2002) analysed the complex phenomenon of the following four collaborative decision-making and synthesized 
approaches: decision analysis, behavioural decision making, game theory and negotiation analysis. Many researchers concentrate on either one or two of these approaches and ignore the other two. The multi-party GDM (Group Decision Making) and negotiation processes typically fall into one of the two classes (Chen et al. 2012): a problem in which two or more independent, concerned parties must make a joint decision, and a problem in which such parties may make a joint decision or may choose to make no decision at all. Most group decision support system tools for choosing from a given set of alternatives involve voting techniques or multi-attribute utility function models. Under multi-criteria, the GDM includes such fields as preference analysis, utility theory, social choice theory, committee decision theory, the theory of voting, game theory, expert evaluation analysis, the aggregation of qualitative factors, economic equilibrium theory, etc. (Hwang, Lin 1987). Therefore, multi-criteria decision methods are increasingly used in this context (Ishizaka, Nemery 2013). Greco et al. (2010) defined multi-criteria decision making (MCDM) as the study of the methods and procedures by which concerns about multiple conflicting criteria can be formally incorporated into the management planning process. Since 1950s and 1960s, when the foundations of modern MCDM methods were laid, many researchers have devoted their time to the development of new MCDM models and techniques (Zavadskas et al. 2014a). A comparative overview of MCDM methods, as well as their usage, was considered by Stanujkic et al. (2013a) and Zavadskas et al. (2014a). MCDM has been used to an incredible extent over the last several decades; the development in the field has accelerated and now seems to continue to grow exponentially. Its role in different application areas has significantly increased, especially as new methods have been developed and old methods have been improved.

The majority of real-world negotiation problems are unique and considerably more complex than the example decisions discussed in the MCDM theory. In multi-criteria GDM (MCGDM), multiple persons are involved. Moving from the single decision-maker to the multiple decision-maker setting introduces a great deal of complexity into analysis (Hwang, Lin 1987), as well as conflict resolving among the members of a group, making a consensus, and the aggregation of personal preferences and/or ratings into overall group ratings. Roszkowska and Wachowicz (2014) indicate that MCDM methods can be very useful in such cases. Managers are faced with the problem of a wide variety of tools (not a lack of appropriate tools) - the inclusion of MCDM methods can be used for the decisions made under high degrees of uncertainty. The sheer variety, however, can be overwhelming without clear guidance on when to use one tool or a combination of tools over another.

The Analytic Hierarchy Process (AHP) method is one of the most used to solve MCGDM problems. With group judgments in the context of the AHP, one would hope for a broad consensus among decision makers. Altuzarra et al. (2007) proposed a new prioritisation Bayesian analysis procedure for AHP-GDM: the aggregation of individual judgements and the aggregation of individual priorities. Bernasconi et al. (2014) focussed on the empirical properties of the group preference aggregation methods in the AHP.

In addition to applying single MCDM methods to real-world decisions, the progression of technology over the past couple of decades has allowed for more complex decision 
analysis methods to develop. This experimentation with combined MCDM methods has provided a whole new approach to decision analysis.

Chu et al. (2007) study the aims to obtain the anticipated achievements of groups through conducting a group-decision comparison. The three multiple-criteria decisionmaking methods used - namely Simple Average Weight, TOPSIS, and VIKOR (Opricovic 1998) - are based on the aggregating function representing "closeness to the ideal point". Both the TOPSIS and VIKOR (Ju, Wang 2013) methods are suitable for assessing similar problems, provide excellent results close to reality and grant a superior analysis.

Considering the relative agreement degrees and the importance of the weights of multiple decision makers, Chen (2015) presented a modified hybrid averaging method with an inclusion-based ordered weighted averaging operation for forming a collective decision environment. He developed an extended TOPSIS method with an inclusion comparison approach for addressing MCGDM problems in the framework of interval-valued intuitionistic fuzzy sets.

The Simple Additive Weighting (SAW) method is the common aggregation method of multi-attribute utility theory for group decisions (Huang et al. 2013).

Wachowicz and Błaszczyk (2013) modified the TOPSIS algorithm in order to make it applicable to negotiation support. They used TOPSIS for a negotiation problem with a continuous negotiation space, for selecting the distance measure for the adequate representation of the negotiator's preferences and for measuring distances for qualitative issues.

Ondrus et al. (2015) demonstrated the design and use of a foresight support system (FSS) combining two MCDM methods: ELECTRE (Roy 1991) and SAW.

Montajabiha (2016) presented a model based on PROMETHEE (Brans, Vincke 1985) in order to solve complex MCGDM problems. He proposed a new version of the PROMETHEE II, aiming at solving MCGDM problems. IFSs are used in order to assess the weights of all criteria and the ratings of each alternative with respect to each criterion.

The use of the mean values of criteria weights and performance ratings, obtained from the respondents involved in an evaluation, can be identified as a common approach, used in many integrations of MCDM methods and GDM techniques, for determining the overall performance ratings of the considered alternatives.

Zavadskas and Turskis (2010) proposed an innovative approach, under the name of the Additive Ratio Assessment (ARAS) method that introduces a virtual alternative, whose ratings can be used to express the decision-maker's preferences for the desired performances of the criteria. Stanujkic et al. (2013b) proposed a new multi-criteria ranking procedure, based on the distance from the decision-maker's preferences, in which the decision-maker was asked to define the preferred performance for each criterion. Stanujkic and Zavadskas (2015) also proposed an extension of the Weighted Sum Method, adapted so as to take into account the decision-maker's preferences for the preferred ratings of the criteria. Finally, Keršulienè et al. (2010) proposed a new effective Step-Wise 
Weight Assessment Ratio Analysis (SWARA) technique, which allows decision-makers to effectively determine the weighting of evaluation criteria, simultaneously proposing new dispute resolution methods from the economic, social and other points of view.

Based on the above-mentioned methods, approaches and techniques, an approach that should allow the decision-makers/experts involved in an evaluation to better express and defend their preferences is proposed in this manuscript. In the proposed approach, the most appropriate alternative is the alternative that has the largest number of appearances in the first position or ranking lists, or is the one determined on the basis of decisionmakers'/experts' negotiations.

Therefore, this manuscript is organized as follows: Section 1 presents the SWARA method and Section 2 presents the ARAS method. The new normalization procedure, proposed by Stanujkic and Zavadskas (2015), is discussed in Section 3, whereas Section 4 presents the ARCAS method adapted for negotiation, and the framework for evaluating the alternatives based on the use of the SWARA and the adapted ARAS methods is presented in Section 5. In Section 6, a case study is considered in order to present the applicability and effectives of the proposed ARCAS method. The conclusions are given in the final section.

\section{SWARA method}

As previously stated, the SWARA method was proposed by Keršuliene et al. (2010). Despite the fact that the SWARA is a newly-proposed method, it is successfully used for determining the weights of evaluation criteria in many MCDM problems. Of many examples, only a few are mentioned here, such as rational dispute resolution (Keršuliene et al. 2010), the architect selection (Keršuliene,, Turskis 2011), the packaging design selection (Stanujkic et al. 2015), and the personnel selection (Karabasevic et al. 2015). Compared to the well-known AHP method, proposed by Saaty (1980), the SWARA method requires a significantly lower number of pairwise comparisons. The first stage of the SWARA method (the expert judgment method - the democratic stage) ranks criteria according to their respective importance. The voting procedures are based on the premise of decision problems to be solved by collectives within the fixed procedures of democratic systems (Ossadnik et al. 2016). Often, the use of voting procedures is found as one of the fundamental principles to solve collective decision problems in group decision and negotiation literature. At the next stage, the members of the expert group team must be consistent with the ranking order determined at the first stage (consistent with the group decision). On this basis, the SWARA method is recommended as more effective in many cases when experienced decision-makers are familiar with MCDM and/or when experts determine the weights of criteria.

The process of determining criteria weights by using the SWARA method is a step-wise procedure:

Step 1. Rank the criteria in descending order, based on their expected importance (the expert judgment method - the democratic stage).

Step 2. (The following stages are autocratic stages). Start from the second criterion 
and express the relative importance of the criterion $j$ in relation to the previous $j-1$ criterion, and do so for each particular criterion. The ratio called the Comparative Importance of the Average Value $s_{j}$ (Kersuliene et al. 2010).

Step 3. Determine the coefficient $k_{j}$ :

$$
k_{j}=\left\{\begin{array}{cc}
1 ; & j=1 \\
s_{j}+1 ; & j>1 .
\end{array}\right.
$$

Step 4. Determine the recalculated weighting factors $q_{j}$ :

$$
q_{j}=\left\{\begin{array}{cc}
1 ; & j=1, \\
\frac{q_{j-1}}{k_{j}} ; & j>1 .
\end{array}\right.
$$

Step 5. Determine the relative weights of the evaluation criteria:

$$
w_{j}=\frac{q_{j}}{\sum_{k=1}^{n} q_{k}},
$$

where $w_{j}$ denotes the relative weight of the criterion $j$.

\section{ARAS method}

When defining the best solution, stakeholders may ask the negotiator to define his aspiration and reservation levels in a form of complete packages comprised of the option values, which will be used in order to define the negotiation space for each criterion (the range of feasible values) (Wachowicz, Błaszczyk 2013). Zavadskas and Turskis (2010) introduced the ARAS method. Nevertheless, the ARAS method is applied so as to solve a number of MCDM problems. In order to enable the use of the ARAS method for solving a much larger number of real-world decision-making problems, grey and fuzzy extensions are also proposed: the ARAS-G (Turskis, Zavadskas 2010b), the ARAS-F (Turskis, Zavadskas 2010a), and the IVTFN extensions (Stanujkic 2015).

Some applications of the ARAS method are listed: the waste dump site selection (Shariati et al. 2014), selecting criteria for building a sustainability assessment (Medineckiene et al. 2015), the evaluation of the existing state of buildings and comparing them with the optimal alternative, which is equal to Nearly Zero-Energy Buildings (Zavadskas et al. 2017), and so on.

The process of solving decision-making problems by using the ARAS method (the ARAS method is very close to the AHP additive form, to the SAW method (MacCrimmon 1968) and some ideas taken from the TOPSIS method (Hwang, Yoon 1981) start by forming a decision matrix. The remaining computational procedure of the ARAS method can be expressed by the following six steps:

Step 1. Determine the optimal performance rating for each criterion and form the ideal alternative $A_{0}=\left\{x_{01}, x_{02}, \ldots, x_{0 n}\right\}$, whose elements are the optimal ratings of the criteria: 
$x_{0 j}=\left\{\begin{array}{c}1.2 \max _{i} x_{i j}, \text { if } x_{o p t} \text { is a priori unknown, and } \\ x_{o p t}, \text { if } x_{o p t} \text { is a priori known, } \\ \max _{i} x_{i j}, \text { if } x_{o p t} \text { is a priori unknown and decision-maker believes that } \max _{i} x_{i j}=x_{o p t}, j \in \Omega_{\max } \\ 0.8 \min _{i} x_{i j}, \text { if } x_{o p t} \text { is a priori unknown, and } \\ \left\{\begin{array}{l}x_{o p t}, \\ \min _{i} x_{i j}, \text { if } x_{o p t} \text { is a priori known, } x_{o p t} \text { is a priori unknown and decision-maker believes that } \min _{i} x_{i j}=x_{o p t}, j \in \Omega_{\min } .\end{array}\right.\end{array}\right.$

where $x_{0 j}$ denotes the optimal rating of the criterion $j, x_{i j}$ denotes the rating of the alternative $i$ with respect to the criterion $j, \Omega_{\max }$ and $\Omega_{\min }$ denote the set of the benefit criteria (the optimisation direction is maximum) and the cost criteria (the optimisation direction is minimum), respectively; $i$ denotes the number of the alternatives; $i=1, \ldots$, $m . j$ denotes the number of the criteria; $j=1, \ldots, n$.

Step 2. Calculating the normalised ratings $r_{i j}$ as follows:

$$
r_{i j}= \begin{cases}\frac{x_{i j}}{\sum_{i=0}^{m} x_{i j}} ; & j \in \Omega_{\max }, \\ \frac{1 / x_{i j}}{\sum_{i=0}^{m} 1 / x_{i j}} ; & j \in \Omega_{\min } .\end{cases}
$$

Step 3. Calculating the weighted normalised ratings as follows:

$$
v_{i j}=w_{j} r_{i j}
$$

where $v_{i j}$ denotes the weighted normalised rating of the alternative $i$ in relation to the criterion $j$.

Step 4. Calculating the overall performance rating, for each alternative as follows:

$$
S_{i}=\sum_{j=1}^{n} v_{i j},
$$

where $S_{i}$ denotes the overall performance rating of the alternative $i$.

Step 5. Calculate the degree of utility for each alternative as follows:

$$
Q_{i}=\frac{S_{i}}{S_{0}},
$$

where $Q_{i}$ denotes the degree of the utility of the alternative $i$, and $S_{0}$ is the overall performance index of the optimal alternative.

Step 6. Rank the considered alternatives by ascending $Q_{i}$ (the alternative is with the largest value of $Q_{i}$ ). 


\section{Normalization procedure based on distances from the decision-maker's preferences}

Based on Weitendorf (1976) and Juttler (1966), Stanujkic et al. (2013b) proposed a new normalization procedure based on the distance from the preferred ratings, which to a greater extent respects the decision-maker's preferences, as follows:

$$
\begin{gathered}
r_{i j}=\frac{x_{i j}-x_{j}^{*}}{x_{j}^{+}-x_{j}^{-}} ; j \in \Omega_{\max }, \text { and } \\
r_{i j}=\frac{x_{j}^{*}-x_{i j}}{x_{j}^{+}-x_{j}^{-}} ; j \in \Omega_{\min },
\end{gathered}
$$

where $x_{j}^{*}$ denotes the preferred rating of the criterion $j, x_{i j}$ denotes the performance rating of the alternative $i$ with respect to the criterion $j, x_{j}^{+}$and $x_{j}^{-}$denote the largest and the smallest performance rating of the criterion $j$, respectively, $\Omega_{\max }$ and $\Omega_{\min }$ are the set of the benefit criteria (maximization criteria) and the cost criteria (minimization criteria), respectively.

Further, Stanujkic and Zavadskas (2015) proposed a much more concise form of Eqs (9) and (10), as follows:

where:

$$
r_{i j}=\frac{x_{i j}-x_{0 j}}{x_{j}^{+}-x_{j}^{-}},
$$

$$
\begin{aligned}
& x_{j}^{+}=\left\{\begin{array}{ll}
\max _{i} x_{i j} ; & j \in \Omega_{\max } \\
\min _{i} x_{i j} ; & j \in \Omega_{\min }
\end{array},\right. \\
& x_{j}^{-}= \begin{cases}\min _{i} x_{i j} ; & j \in \Omega_{\min } \\
\max _{i} x_{i j} ; & j \in \Omega_{\max }\end{cases}
\end{aligned}
$$

and $x_{0 j}$ denotes the optimal rating of the criterion $j$.

By using Eq. (11), the normalized rating of the alternative $i$ in relation to the criterion $j$ is:

- positive, $r_{i j}>0$; if the rating $x_{i j}$ is higher than the preferred one,

- equal to zero, $r_{i j}=0$; if the rating $x_{i j}$ is equal to the preferred one, and

- negative, $r_{i j}<0$; if the rating $x_{i j}$ is lower than the preferred one.

On the basis of the use of that normalization procedure, Stanujkic and Zavadskas (2015) also proposed some additional parameters, which can be very useful in different analyses and negotiation processes, such as:

- the largest weighted normalized deviation in the desired direction $d_{i}^{+}$max and the largest weighted normalized deviation in the undesired direction $d_{i}^{-\max }$ of the alternative $i$,

- the number of the criteria according to which the alternative $i$ achieves $n_{i}^{0}$ or exceeds $n_{i}^{+}$performance ratings, and

$-\bar{S}_{i}^{+}$denotes the average weighted normalized ratings achieved on the basis of the criteria, so that $r_{i j}>0$. 
The values of additional parameters can be determined as follows:

$$
\begin{aligned}
d_{i}^{+\max } & =\max _{j} w_{j} r_{i j} ; \quad r_{i j} \geq 0, \\
d_{i}^{-\min } & =\min _{j} w_{j} r_{i j} ; \quad r_{i j} \leq 0, \\
\bar{S}_{i}^{+} & =\frac{1}{n_{i}^{+}} \sum_{r_{i j}>0} w_{j} r_{i j} .
\end{aligned}
$$

The above-mentioned parameters and their usage are considered in much more detail in Stanujkic and Zavadskas (2015), where they also proposed the usage of the compensation coefficient $c_{i}$ and the adjusted overall performance rating $S_{i}$, as follows:

$$
\begin{gathered}
c_{i}=\lambda d_{i}^{+\max }+(1-\lambda) \bar{S}_{i}^{+}, \\
S_{i}^{\prime}=S_{i}-\gamma c_{i},
\end{gathered}
$$

where $\lambda$ is the coefficients; $\lambda \in[0,1]$ and is usually set at $0.5, \gamma$ is the coefficient; $\gamma \in[0$, 1], $c_{i}>0$ and $S_{i}>0$.

The proposed compensation coefficient should provide adequate ratios, or to be more precise, such that would be acceptable for the decision-maker, ranging between the greatest possible value of $S_{i}$ and that which better matches the preferred performance ratings.

\section{ARCAS method adapted for negotiation}

A good MCDM model should allow decision-makers to establish the criteria of relevant preference formats. In order to structure discussions and analyses, the group generally recourses to techniques such as Delphi (Linstone, Turoff 1975), the focus group and Estimate-Talk-Estimate. In the proposed adoption of the ARAS method (ARCAS (Additive Ratio Compromise ASsessment)), the following two modifications should be made:

- normalization should be performed by using Eq. (11) instead of Eq. (5);

- as a result of that, the overall performance ratings of the alternatives may have values ranging between -1 and 1 , instead of those ranging between 0 and 1 in the original version of the ARAS method, for which reason the ranking of the alternatives should be performed on the basis of $S_{i}$ instead of $Q_{i}$.

Based on the above, the computational procedure of the ARCAS method, adapted ARAS methods, can be presented as follows (Fig. 1). 


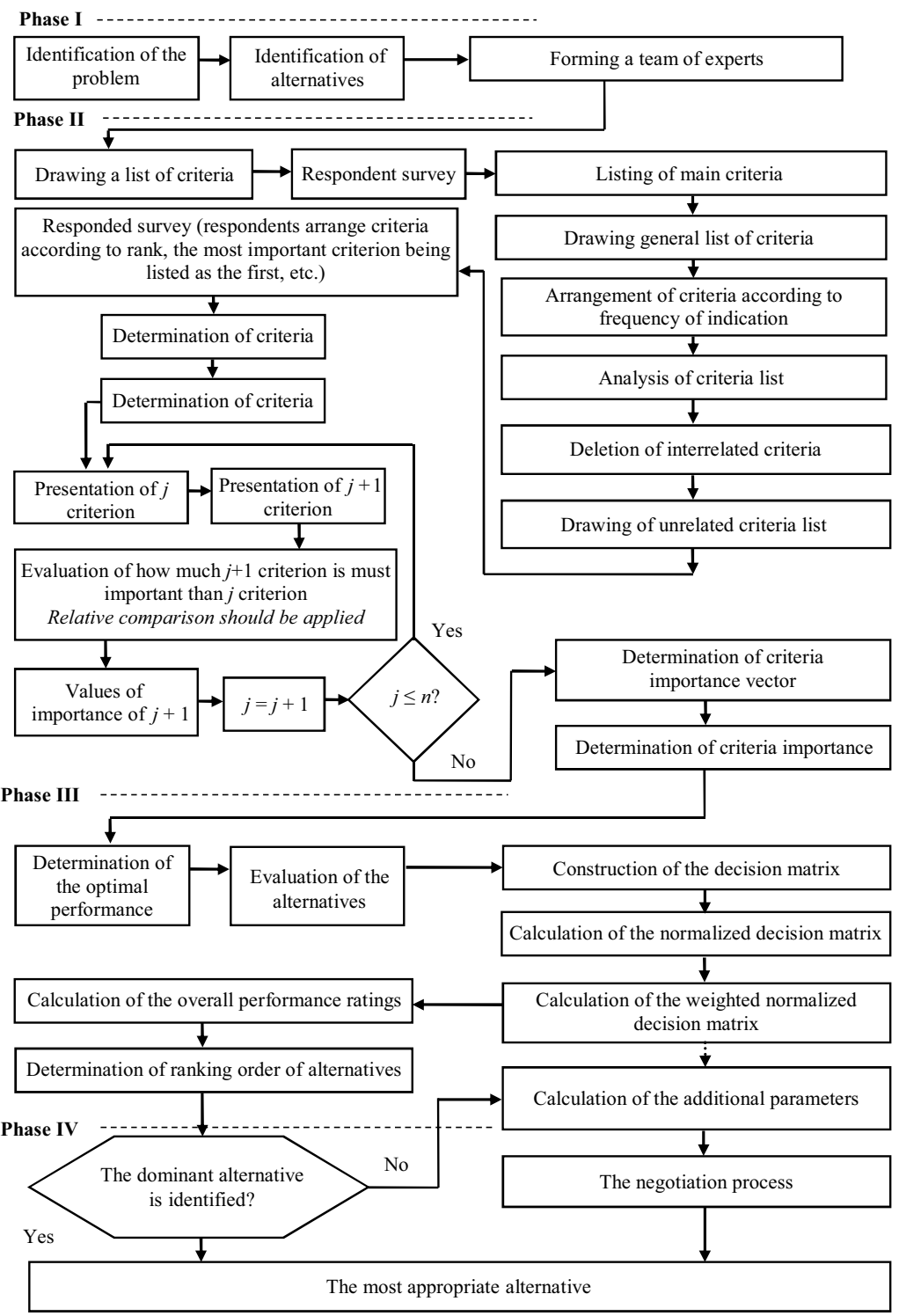

Fig. 1. Algorithm of the ARCAS framework

\section{Integrated ARCAS group MCDM framework based on the SWARA and the adapted ARAS methods}

The selection of a proper problem solution strategy is of major importance, as practice is intrinsically collaborative, within knowledge-rich and multi-functional working environments (Peldschus et al. 2010). The proposed ARCAS framework is based on the use of the SWARA and the adapted ARAS methods, and can accurately be expressed through the following phases and corresponding steps: 
Phase I Form a group of experts, who will carry out the evaluation and determine a set of available alternatives.

Phase II Determine the set of the evaluation criteria, the relevance and weights of the evaluation criteria.

Step 2.1. Determine the set of the evaluation criteria. In this step, the experts determine a set of the evaluation criteria.

Step 2.2. Set the desired level of rating for each evaluation criterion. After defining the set of the evaluation criteria, each expert and/or decision-maker defines the desired level of ratings for each single selected criterion by applying the ratings in the interval 1-7. The meanings of these ratings are shown in Table 1.

Table 1. Ratings for evaluating criteria

\begin{tabular}{cc}
\hline Ratings & Meaning \\
\hline 1 & Very Low \\
\hline 2 & Low \\
\hline 3 & Medium Low \\
\hline 4 & Medium \\
\hline 5 & Medium High \\
\hline 6 & High \\
\hline 7 & Very High \\
\hline
\end{tabular}

Step 2.3. Determine the relevance of the evaluation criteria. The relevance of the evaluation criteria, as well as their ranking order, sorted by relevance, can be determined as follows:

$$
o_{j}=\frac{\sum_{k=1}^{K} q_{j}^{k}}{K},
$$

where $o_{j}$ denotes the relative relevance of the criterion $j, q_{j}^{k}$ denotes the ratings of the criterion $j$ obtained from the expert $k$, and $K$ is the number of the experts.

After that, the criteria are sorted based on their $o_{j}$ in descending order and the obtained ranking order is further used in the SWARA method.

Step 2.4. Determine the weights of the evaluation criteria. In this step, by applying the SWARA method, the experts and/or the decision-maker involved in the evaluation determine the weights of the evaluation criteria.

By doing so, each expert and/or decision-maker determines his/her own weight of the criteria.

Phase III Evaluation of Alternatives.

Step 3.1. Evaluate the alternatives in relation to the selected set of criteria. In this step, by applying the ratings in the interval 1-7, the experts and/or the decision-maker perform the evaluation of the alternatives in relation to the selected criteria. The meanings of the ratings used for evaluating the alternatives are accounted for in Table 2. 
Table 2. Ratings for evaluating alternatives

\begin{tabular}{cc}
\hline Ratings & Meaning \\
\hline 1 & Very Poor \\
\hline 2 & Poor \\
\hline 3 & Medium Poor \\
\hline 4 & Fair \\
\hline 5 & Medium Good \\
\hline 6 & Good \\
\hline 7 & Very Good \\
\hline
\end{tabular}

Step 4. Determine the overall performance rating for each alternative. In this step, by applying the ARCAS method, each expert and/or decision-maker involved in the evaluation determines his/her own overall ratings for the considered alternatives.

Contrary to traditional approaches, which are most commonly based on the ranking based on average values, in the proposed approach each expert has formed his/her own ranking order of the alternatives.

Phase IV Negotiation and selection of the most appropriate alternative.

As a result of performing Phase II of the proposed approach, the $K$ ranking orders of the alternatives are obtained.

In the particular cases, when an alternative is the best placed of all in the ranking lists, it is not difficult to choose the most appropriate alternative.

However, in many cases of solving real-world decision-making problems, experts can be expected to propose different ranking orders, as well as different alternatives, as the most appropriate ones. By using the Delphi technique experts can resolve their differences in opinions through one or more iterations and reach a compromise as a result of negotiations:

- change their attitudes regarding the initial preferred ratings and/or weights of the criteria, and make a re-determination of $S_{i}$ and the ranking orders,

- change the ranking orders of the alternatives based on the additional parameters and their perceptions, and

- change the ranking order of the alternatives based on $S_{i}^{\prime}$ values in cases when more than one has the $S_{i}$ value greater than zero.

\section{Case study}

In this section, the usage of the proposed ARCAS approach is demonstrated on a real case of the sales personnel selection. MaxMobil Telecommunications Company needs sales personnel for its branch office in the interior of the country. A team of three experts in the field of human resource management has been formed with the aim of carrying out an evaluation of the candidates.

At the beginning of the evaluation, the team of experts define a set of evaluation criteria. In this case, the team of experts have chosen the following criteria:

- Work experience $\left(C_{1}\right)$, 
- Oral communication skills $\left(C_{2}\right)$,

- Academic degree $\left(C_{3}\right)$,

- Analytical thinking $\left(C_{4}\right)$,

- Working on a team $\left(C_{5}\right)$,

- Computer skills $\left(C_{6}\right)$, and

- Fluency in foreign languages $\left(C_{7}\right)$.

After that, the experts set the preferred rating levels for each evaluation criterion. The preferred ratings obtained from the three experts are shown in Table 3.

Table 3. The preferred ratings (PR) of evaluation criteria

\begin{tabular}{cccccccc}
\hline Criteria & $C_{1}$ & $C_{2}$ & $C_{3}$ & $C_{4}$ & $C_{5}$ & $C_{6}$ & $C_{7}$ \\
\hline$E_{1}$ & 6 & 6 & 4 & 5 & 4 & 4 & 3 \\
\hline$E_{2}$ & 5 & 4 & 5 & 4 & 3 & 3 & 3 \\
\hline$E_{3}$ & 5 & 5 & 4 & 4 & 4 & 4 & 4 \\
\hline Relevance & 5.33 & 5.00 & 4.33 & 4.33 & 3.67 & 3.67 & 3.33 \\
\hline
\end{tabular}

The relevance of the evaluation criteria, determined by Eq. (19), is also accounted for in Table 3.

The next step in this phase is the determination of the weights of the criteria, wherein each expert determines his/her own weight by using the SWARA method. The weights of the criteria obtained from the three experts are given in Tables 4, 5, 6 and 7.

In the next phase, Phase III, the experts have done an evaluation of the alternatives in relation to the set of the evaluation criteria. The obtained ratings, as well as the weights and preferred ratings obtained from the three experts, are presented in Tables 8, 9 and 10.

The normalized decision matrix and the weighted normalized decision matrix formed on the basis of the responses obtained from the first of the three experts are shown in Tables 11 and 12 .

Table 4. The responses obtained from the first of the three experts and the weights of the criteria

\begin{tabular}{ccccc}
\hline Criteria & $s_{j}$ & $k_{j}$ & $q_{j}$ & $w_{j}$ \\
\hline$C_{1}$ & & 1 & 1.00 & 0.25 \\
\hline$C_{2}$ & 0.25 & 1.25 & 0.80 & 0.20 \\
\hline$C_{3}$ & 0.1 & 1.1 & 0.73 & 0.18 \\
\hline$C_{4}$ & 0.3 & 1.3 & 0.56 & 0.14 \\
\hline$C_{5}$ & 0.2 & 1.2 & 0.47 & 0.12 \\
\hline$C_{6}$ & 0.5 & 1.5 & 0.31 & 0.08 \\
\hline$C_{7}$ & 0.8 & 1.8 & 0.17 & 0.04 \\
\hline & & & 4.04 & 1.00 \\
\cline { 3 - 5 } & & &
\end{tabular}

Table 5. The responses obtained from the second of the three experts and the weights of the criteria

\begin{tabular}{ccccc}
\hline Criteria & $s_{j}$ & $k_{j}$ & $q_{j}$ & $w_{j}$ \\
\hline$C_{1}$ & & 1 & 1.00 & 0.22 \\
\hline$C_{2}$ & 0.15 & 1.15 & 0.87 & 0.20 \\
\hline$C_{3}$ & 0.05 & 1.05 & 0.83 & 0.19 \\
\hline$C_{4}$ & 0.25 & 1.25 & 0.66 & 0.15 \\
\hline$C_{5}$ & 0.3 & 1.3 & 0.51 & 0.11 \\
\hline$C_{6}$ & 0.4 & 1.4 & 0.36 & 0.08 \\
\hline$C_{7}$ & 0.7 & 1.7 & 0.21 & 0.05 \\
\hline & & & 4.45 & 1.00 \\
\cline { 3 - 5 } & & &
\end{tabular}


Table 6. The responses obtained from the third of the three experts and the weights of the criteria

\begin{tabular}{ccccc}
\hline Criteria & $s_{j}$ & $k_{j}$ & $q_{j}$ & $w_{j}$ \\
\hline$C_{1}$ & & 1 & 1.00 & 0.25 \\
\hline$C_{2}$ & 0.25 & 1.25 & 0.80 & 0.20 \\
\hline$C_{3}$ & 0.1 & 1.1 & 0.73 & 0.18 \\
\hline$C_{4}$ & 0.3 & 1.3 & 0.56 & 0.14 \\
\hline$C_{5}$ & 0.2 & 1.2 & 0.47 & 0.12 \\
\hline$C_{6}$ & 0.5 & 1.5 & 0.31 & 0.08 \\
\hline$C_{7}$ & 0.8 & 1.8 & 0.17 & 0.04 \\
\hline & & & 4.04 & 1.00 \\
\cline { 4 - 5 } & & & &
\end{tabular}

Table 7. The weights of the criteria obtained from the three experts

\begin{tabular}{cccc}
\hline & $E_{1}$ & $E_{2}$ & $E_{3}$ \\
\hline Criteria & $w^{1}{ }_{j}$ & $w^{2}{ }_{j}$ & $w^{3}{ }_{j}$ \\
\hline$C_{1}$ & 0.25 & 0.22 & 0.25 \\
\hline$C_{2}$ & 0.20 & 0.20 & 0.20 \\
\hline$C_{3}$ & 0.18 & 0.19 & 0.18 \\
\hline$C_{4}$ & 0.14 & 0.15 & 0.14 \\
\hline$C_{5}$ & 0.12 & 0.11 & 0.12 \\
\hline$C_{6}$ & 0.08 & 0.08 & 0.08 \\
\hline$C_{7}$ & 0.04 & 0.05 & 0.04 \\
\hline
\end{tabular}

Table 8 . The ratings, weighting and preferred ratings (PR) obtained from the first of the three experts

\begin{tabular}{cccccccc}
\hline Criteria & $C_{1}$ & $C_{2}$ & $C_{3}$ & $C_{4}$ & $C_{5}$ & $C_{6}$ & $C_{7}$ \\
\hline$w_{j}$ & 0.25 & 0.20 & 0.18 & 0.14 & 0.12 & 0.08 & 0.04 \\
\hline$P R$ & 6 & 6 & 4 & 5 & 4 & 4 & 3 \\
\hline$A_{1}$ & 5 & 4 & 6 & 3 & 4 & 3 & 3 \\
\hline$A_{2}$ & 7 & 4 & 6 & 4 & 4 & 4 & 4 \\
\hline$A_{3}$ & 4 & 5 & 6 & 3 & 3 & 5 & 5 \\
\hline$A_{4}$ & 5 & 4 & 5 & 4 & 3 & 6 & 5 \\
\hline
\end{tabular}

Table 9. The ratings, weighting and preferred (PR) ratings obtained from the second of the three experts

\begin{tabular}{llllllll}
\hline Criteria & $C_{1}$ & $C_{2}$ & $C_{3}$ & $C_{4}$ & $C_{5}$ & $C_{6}$ & $C_{7}$ \\
\hline$w_{j}$ & 0.22 & 0.20 & 0.19 & 0.15 & 0.11 & 0.08 & 0.05 \\
\hline$P R$ & 5 & 4 & 5 & 4 & 3 & 3 & 3 \\
\hline$A_{1}$ & 5 & 4 & 5 & 3 & 3 & 3 & 4 \\
\hline$A_{2}$ & 6 & 4 & 6 & 2 & 3 & 3 & 4 \\
\hline$A_{3}$ & 4 & 6 & 6 & 2 & 4 & 3 & 4 \\
\hline$A_{4}$ & 4 & 5 & 4 & 3 & 4 & 4 & 5 \\
\hline
\end{tabular}

Table 10. The ratings, weighting and preferred ratings (PR) obtained from the third of the three experts

\begin{tabular}{cccccccc}
\hline Criteria & $C_{1}$ & $C_{2}$ & $C_{3}$ & $C_{4}$ & $C_{5}$ & $C_{6}$ & $C_{7}$ \\
\hline$w_{j}$ & 0.25 & 0.20 & 0.18 & 0.14 & 0.12 & 0.08 & 0.04 \\
\hline$P R$ & 5 & 5 & 4 & 4 & 4 & 4 & 4 \\
\hline$A_{1}$ & 6 & 3 & 6 & 4 & 3 & 4 & 2 \\
\hline$A_{2}$ & 7 & 3 & 5 & 2 & 4 & 4 & 4 \\
\hline$A_{3}$ & 4 & 5 & 6 & 4 & 4 & 4 & 3 \\
\hline$A_{4}$ & 5 & 4 & 5 & 3 & 5 & 5 & 5 \\
\hline
\end{tabular}


Table 11. The normalized decision matrix based on the responses obtained from the first of the three experts

\begin{tabular}{cccccccc}
\hline Criteria & $C_{1}$ & $C_{2}$ & $C_{3}$ & $C_{4}$ & $C_{5}$ & $C_{6}$ & $C_{7}$ \\
\hline$A_{1}$ & -0.33 & -2.00 & 2.00 & -2.00 & 0.00 & -0.33 & 0.00 \\
\hline$A_{2}$ & 0.33 & -2.00 & 2.00 & -1.00 & 0.00 & 0.00 & 0.50 \\
\hline$A_{3}$ & -0.67 & -1.00 & 2.00 & -2.00 & -1.00 & 0.33 & 1.00 \\
\hline$A_{4}$ & -0.33 & -2.00 & 1.00 & -1.00 & -1.00 & 0.67 & 1.00 \\
\hline
\end{tabular}

Table 12. The weighted normalized decision matrix based on the responses obtained from the first of the three experts

\begin{tabular}{cccccccc}
\hline Criteria & $C_{1}$ & $C_{2}$ & $C_{3}$ & $C_{4}$ & $C_{5}$ & $C_{6}$ & $C_{7}$ \\
\hline$A_{1}$ & -0.08 & -0.40 & 0.36 & -0.28 & 0.00 & -0.03 & 0.00 \\
\hline$A_{2}$ & 0.08 & -0.40 & 0.36 & -0.14 & 0.00 & 0.00 & 0.02 \\
\hline$A_{3}$ & -0.17 & -0.20 & 0.36 & -0.28 & -0.12 & 0.03 & 0.04 \\
\hline$A_{4}$ & -0.08 & -0.40 & 0.18 & -0.14 & -0.12 & 0.05 & 0.04 \\
\hline
\end{tabular}

In the same way, the normalized decision matrix and the weighted normalized decision matrix for the second and the third experts are calculated.

The overall performance ratings of the considered alternatives obtained on the basis of the responses of the three experts, the ranking orders and the additional parameters for a detailed analysis are given in Tables 13, 14, and 15.

The overall performance ratings of the considered alternatives obtained from the three experts are presented in Table 16.

Table 13. Additional parameters obtained on the basis of the responses of the first of the three experts

\begin{tabular}{cccccccc}
\hline & $S_{i}$ & Rank & $d_{i}^{+\max }$ & $d_{i}^{-\max }$ & $n_{i}^{0}$ & $n_{i}^{+}$ & $S^{+}$ \\
\hline$A_{1}$ & -0.42 & 3 & 0.36 & -0.40 & 2 & 1 & 0.36 \\
\hline$A_{2}$ & -0.07 & 1 & 0.36 & -0.40 & 2 & 3 & 0.46 \\
\hline$A_{3}$ & -0.33 & 2 & 0.36 & -0.28 & 0 & 3 & 0.43 \\
\hline$A_{4}$ & -0.46 & 4 & 0.18 & -0.40 & 0 & 3 & 0.27 \\
\hline
\end{tabular}

Table 14. Additional parameters obtained on the basis of the responses of the second of the three experts

\begin{tabular}{cccccccc}
\hline & $S_{i}$ & Rank & $d_{i}^{+\max }$ & $d_{i}^{-\max }$ & $n_{i}^{0}$ & $n_{i}^{+}$ & $S^{+}$ \\
\hline$A_{1}$ & -0.10 & 4 & 0.05 & -0.15 & 5 & 1 & 0.05 \\
\hline$A_{2}$ & -0.04 & 3 & 0.11 & -0.30 & 3 & 3 & 0.25 \\
\hline$A_{3}$ & 0.04 & 1 & 0.20 & -0.30 & 1 & 4 & 0.45 \\
\hline$A_{4}$ & 0.04 & 2 & 0.11 & -0.15 & 0 & 4 & 0.39 \\
\hline
\end{tabular}


Table 15. Additional parameters obtained on the basis of the responses of the third of the three experts

\begin{tabular}{cccccccc}
\hline & $S_{i}$ & Rank & $d_{i}^{+\max }$ & $d_{i}^{-\max }$ & $n_{i}^{0}$ & $n_{i}^{+}$ & $S^{+}$ \\
\hline$A_{1}$ & 0.16 & 3 & 0.36 & -0.20 & 2 & 2 & 0.44 \\
\hline$A_{2}$ & 0.01 & 4 & 0.18 & -0.20 & 3 & 2 & 0.35 \\
\hline$A_{3}$ & 0.26 & 1 & 0.36 & -0.08 & 4 & 1 & 0.36 \\
\hline$A_{4}$ & 0.16 & 2 & 0.18 & -0.10 & 1 & 4 & 0.33 \\
\hline
\end{tabular}

Table 16. The overall performance ratings obtained from the three experts

\begin{tabular}{cccccccc}
\hline & & $E_{1}$ & & & $E_{2}$ & & $E_{3}$ \\
\hline & $S_{i}$ & Rank & $S_{i}$ & Rank & $S_{i}$ & Rank \\
\hline$A_{1}$ & -0.42 & 3 & -0.10 & 4 & 0.16 & 3 \\
\hline$A_{2}$ & -0.07 & 1 & -0.04 & 3 & 0.01 & 4 \\
\hline$A_{3}$ & -0.33 & 2 & 0.041 & 1 & 0.26 & 1 \\
\hline$A_{4}$ & -0.46 & 4 & 0.036 & 2 & 0.16 & 2 \\
\hline
\end{tabular}

As can be seen from Table 16, the candidate $A_{3}$ is twice ranked in the first position, on the basis of the opinions of the experts $E_{2}$ and $E_{3}$, whereas the candidate $A_{2}$ is once ranked in the first position, on the basis of the opinion of the expert $E_{1}$.

Based on the above-mentioned, it can be concluded that the candidate A3 is probably the most appropriate candidate. In this case, the first of the three experts changed his ratings in relation to the criterion 4 , in the second iteration after having seen the results obtained from the other experts, as is shown in Tables 17, 18 and 19.

Table 17. The ratings and preferred ratings (PR) obtained from the first of the three experts in the second iteration

\begin{tabular}{cccccccc}
\hline Criteria & $C_{1}$ & $C_{2}$ & $C_{3}$ & $C_{4}$ & $C_{5}$ & $C_{6}$ & $C_{7}$ \\
\hline$P R$ & 5 & 5 & 4 & 5 & 4 & 4 & 3 \\
\hline$A_{1}$ & 5 & 4 & 6 & 3 & 4 & 3 & 3 \\
\hline$A_{2}$ & 7 & 4 & 6 & 4 & 4 & 4 & 4 \\
\hline$A_{3}$ & 4 & 5 & 6 & 4 & 4 & 5 & 5 \\
\hline$A_{4}$ & 5 & 4 & 5 & 4 & 3 & 6 & 5 \\
\hline
\end{tabular}

Table 18. The weights of the criteria obtained from the first of the three experts in the second iteration

\begin{tabular}{ccccc}
\hline Criteria & $s_{j}$ & $k_{j}$ & $q_{j}$ & $w_{j}$ \\
\hline$C_{1}$ & & 1 & 1.00 & 0.24 \\
\hline$C_{2}$ & 0.25 & 1.25 & 0.80 & 0.19 \\
\hline$C_{3}$ & 0.1 & 1.1 & 0.73 & 0.18 \\
\hline$C_{4}$ & 0.3 & 1.3 & 0.56 & 0.14 \\
\hline$C_{5}$ & 0.1 & 1.1 & 0.51 & 0.12 \\
\hline$C_{6}$ & 0.5 & 1.5 & 0.34 & 0.08 \\
\hline$C_{7}$ & 0.8 & 1.8 & 0.19 & 0.05 \\
\hline & & & 4.12 & 1.00
\end{tabular}


Table 19. Additional parameters obtained on the basis of the responses of the first of the three experts in the second iteration

\begin{tabular}{cccccccc}
\hline & $S_{i}$ & Rank & $d_{i}^{+\max }$ & $d_{i}^{-\max }$ & $n_{i}^{0}$ & $n_{i}^{+}$ & $S^{+}$ \\
\hline$A_{1}$ & -0.140 & 3 & 0.35 & -0.27 & 3 & 1 & 0.35 \\
\hline$A_{2}$ & 0.208 & 2 & 0.35 & -0.19 & 2 & 3 & 0.18 \\
\hline$A_{3}$ & 0.209 & 1 & 0.35 & -0.14 & 2 & 3 & 0.14 \\
\hline$A_{4}$ & -0.176 & 4 & 0.18 & -0.19 & 1 & 3 & 0.09 \\
\hline
\end{tabular}

After changing the rating of the criterion $C_{4}$, the alternative $A_{3}$ has a better matching related to the preferred performance ratings and on this basis it becomes the best-ranked alternative. In this way, a consensus among the experts is also reached.

\section{Conclusions}

In contrast to a number of MCDM approaches proposing an evaluation based on group criteria weights and group performance ratings, a specific approach adapted for negotiation is proposed in this manuscript.

In the proposed approach, each expert and/or decision-maker involved in an evaluation sets his/her own preferred ratings of the evaluation criteria and makes his/her own ranking list of alternatives. After that, the alternative with the largest number of appearances in the first position on such ranking lists is declared the most acceptable one.

In cases when it is difficult to determine the dominance of a certain alternative in relation to another, the experts and/or decision-makers involved in the evaluation should select the most suitable alternative based on their negotiations.

The proposed ARCAS approach is based on the use of the SWARA method and the ARAS method, with a new normalization procedure. In this approach, the SWARA method is used for determining the weights of the evaluation criteria, whereas the ARCAS method is used for evaluating the alternatives and for forming the individual ranking order for each expert and/or decision-maker involved in the evaluation. The SWARA method was chosen because its usage requires a significantly smaller number of pairwise comparisons compared to the well-known AHP method. Furthermore, the SWARA method could be more efficient compared to the AHP method when experts are involved in evaluation, i.e. determining the weights of criteria.

The ARAS method also has a comprehensive and easy to use computational procedure, which is why it was chosen for the evaluation of the alternatives. Using the ARAS method with the new normalization procedure allows the forming of a subset containing the alternatives whose performance ratings are to a greater extent in accordance with the decision-makers' preferences.

The proposed normalization procedure, adapted for normalization based on preferred performance ratings, also provides some significant parameters that can be very useful in the negotiation process. 
The ARCAS method can equally be used together with other classical MCDM methods. However, a significant superiority of the ARCAS method over the other MCDM methods could be expected when one or more criterion functions are significantly non-linear. Therefore, solving complex decision-making problems based on the participation of a larger number of experts and the usage of a smaller number of more complex evaluation criteria rather than a significantly larger number of well-defined criteria could be identified as one of the expected areas of the further usage of the ARCAS method.

The following can be specified as the three main advantages (+) and disadvantages (-) of the ARCAS approach:

$(+)$ A larger number of group members contribute many pieces of information to the knowledge base, a greater number of alternatives available for solving a problem are generated and the personal biases they have introduced due to individual decision-making are eliminated. Thus, the solution becomes more reliable as compared to individual decisions and increases the quality of the decision.

(-) This is a time-consuming process. When solving very important and crucial problems, influence groups usually manipulate the group decision by directing it according to their own liking and interest, and sometimes decisions made by the group members are a compromise between the various options offered by the group members.

$(+)$ The implementation of decisions will be more effective as the people who are going to implement them are exactly those who also participated in decision-making and such decisions will also be accepted better.

Finally, the considered case study on the selection of the candidates has confirmed the applicability of the proposed approach.

\section{References}

Altuzarra, A.; Moreno-Jiménez, J. M.; Salvador, M. 2007. A Bayesian priorization procedure for AHP-group decision making, European Journal of Operational Research 182(1): 367-382. https://doi.org/10.1016/j.ejor.2006.07.025

Bernasconi, M.; Choirat, C.; Seri, R. 2014. Empirical properties of group preference aggregation methods employed in AHP: theory and evidence, European Journal of Operational Research 232(3): 584-592. https://doi.org/10.1016/j.ejor.2013.06.014

Brans, J. P.; Vincke, P. 1985. A preference ranking organization method: the PROMETHEE method for MCDM, Management Science 31(6): 647-656. https://doi.org/10.1287/mnsc.31.6.647

Chen, T.-Y. 2015. The inclusion-based TOPSIS method with interval-valued intuitionistic fuzzy sets for multiple criteria group decision making, Applied Software Computing 26: 57-73.

https://doi.org/10.1016/j.asoc.2014.09.015

Chen, Y.; Kilgour, D. M.; Hipel, K. W. 2012. A decision rule aggregation approach to multiple criteria-multiple participant sorting, Group Decision and Negotiation 21(5): 727-745.

https://doi.org/10.1007/s10726-011-9246-6

Chu, M.-T.; Shyu, J.; Tzeng, G.-H.; Khosla, R. 2007. Comparison among three analytical methods for knowledge communities group-decision analysis, Expert Systems with Applications 33(4): 1011-1024. https://doi.org/10.1016/j.eswa.2006.08.026 
Greco, S.; Ehrgott, M.; Figueira, J. R. (Eds.). 2010. Trends in multiple criteria decision analysis. New York: Springer-Verlag.

Huang, Y.-S.; Chang, W.-C.; Li, W.-H.; Lin, Z.-L. 2013. Aggregation of utility-based individual preferences for group decision-making, European Journal of Operational Research 229(2): 462 469. https://doi.org/10.1016/j.ejor.2013.02.043

Hwang, C. L.; Lin, M. J. 1987. Group decision making under multiple criteria: methods and applications (Vol. 281). Berlin Heidelberg: Springer-Verlag.

https://doi.org/10.1007/978-3-642-61580-1

Hwang, C. L.; Yoon, K. 1981. Multiple attribute decision making: methods and applications. New York: Springer-Verlag. https://doi.org/10.1007/978-3-642-48318-9

Ishizaka, A.; Nemery, P. 2013. A multi-criteria group decision framework for partner grouping when sharing facilities, Group Decision and Negotiation 22(4): 773-799.

https://doi.org/10.1007/s10726-012-9292-8

Ju, Y.; Wang, A. 2013. Extension of VIKOR method for multi-criteria group decision making problem with linguistic information, Applied Mathematical Modelling 37(5): 3112-3125.

https://doi.org/10.1016/j.apm.2012.07.035

Juttler, H. 1966. Untersuchungen zur Fragen der Operationsforschung und ihrer Anwendungsmoglichkeiten auf okonomische Problemstellungen unter besonderer Berucksichtigung der Spieltheorie [Investigations on the question of operational research and its application to economic problems with special consideration of the game theory]: Doctoral dissertation. Fakultat der Humboldt-Universitat, Berlin.

Karabasevic, D.; Stanujkic. D.; Urosevic, S.; Maksimovic, M. 2015. Selection of candidates in the mining industry based on the application of the SWARA and the MULTIMOORA methods, Acta Montanistica Slovaca 20(2): 116-124.

Keršuliene, V.; Turskis, Z. 2011. Integrated fuzzy multiple criteria decision making model for architect selection, Technological and Economic Development of Economy 17(4): 645-666. https://doi.org/10.3846/20294913.2011.635718

Kersuliene, V.; Zavadskas, E. K.; Turskis, Z. 2010. Selection of rational dispute resolution method by applying new step-wise weight assessment ratio analysis (SWARA), Journal of Business Economics and Management 11(2): 243-258. https://doi.org/10.3846/jbem.2010.12

Linstone, H. A.; Turoff, M. 1975. The Delphi method: techniques and applications. London: Addison-Wesley.

MacCrimmon, K. R. 1968. Decision making among multiple-attribute alternatives: a survey and consolidated approach (No. RM-4823-ARPA). Santa Monica: RAND Corporation.

Medineckiene, M.; Zavadskas, E. K.; Björk, F.; Turskis, Z. 2015. Multi-criteria decision-making system for sustainable building assessment/certification, Archives of Civil and Mechanical Engineering 15(1): 11-18. https://doi.org/10.1016/j.acme.2014.09.001

Montajabiha, M. 2016. An extended PROMETHE II multi-criteria group decision making technique based on intuitionistic fuzzy logic for sustainable energy planning, Group Decision and Negotiation 25(2): 221-244. https://doi.org/10.1007/s10726-015-9440-z

Munier, B. R.; Shakun, M. F. 1988. Compromise, negotiation and group decision. Holland: D. Reidel Publishing Company. https://doi.org/10.1007/978-94-009-4021-5

Ondrus, J.; Bui, T.; Pigneur, Y. 2015. A foresight support system using MCDM methods, Group Decision and Negotiation 24(2): 333-358. https://doi.org/10.1007/s10726-014-9392-8

Opricovic, S. 1998. Visekriterijumska optimizacija sistema u gradjevinarstvu [Multicriteria optimization of civil engineering systems]: Doctoral dissertation. Faculty of Civil Engineering, Belgrade. 
Ossadnik, W.; Schinke, S.; Kaspar, R. H. 2016. Group aggregation techniques for analytic hierarchy process and analytic network process: a comparative analysis, Group Decision and Negotiation 25(2): 421-457. https://doi.org/10.1007/s10726-015-9448-4

Peldschus, F.; Zavadskas, E. K.; Turskis, Z.; Tamosaitiene, J. 2010. Sustainable assessment of construction site by applying game theory, Inzinerine Ekonomika-Engineering Economics 21(3): 223-237.

Raiffa, H.; Richardson, J.; Metcalfe, D. 2002. Negotiation analysis: the science and art of collaborative decision making. Cambridge, Massachusetts: The Belknap Press of Harvard University Press.

Roszkowska, E.; Wachowicz, T. 2014. The multi-criteria negotiation analysis based on the membership function, Studies in Logic, Grammar and Rhetoric 37(1): 195-217.

Roy, B. 1991. The outranking approach and the foundation of ELECTRE methods, Theory and Decision 31(1): 49-73. https://doi.org/10.1007/BF00134132

Saaty, T. L. 1980. The analytic hierarchy process: planning, priority setting, resource allocation. New York: McGraw-Hill.

Shariati, Sh.; Yazdani-Chamzini, A.; Salsani, A.; Tamosaitiene, J. 2014. Proposing a new model for waste dump site selection: case study of Ayerma Phosphate mine, Inzinerine EkonomikaEngineering Economics 25(4): 410-419. https://doi.org/10.5755/j01.ee.25.4.6262

Stanujkic, D. 2015. Extension of the ARAS method for decision-making problems with intervalvalued triangular fuzzy numbers, Informatica 26(2): 335-355.

https://doi.org/10.15388/Informatica.2015.51

Stanujkic, D.; Djordjevic, B.; Djordjevic, M. 2013a. Comparative analysis of some prominent MCDM methods: a case of ranking Serbian banks, Serbian Journal of Management 8(2): $213-$ 241. https://doi.org/10.5937/sjm8-3774

Stanujkic, D.; Karabasevic, D.; Zavadskas, E. K. 2015. A framework for the selection of a packaging design based on the SWARA method, Inzinerine Ekonomika-Engineering Economics 26(2): 181-187. https://doi.org/10.5755/j01.ee.26.2.8820

Stanujkic, D.; Magdalinovic, N.; Jovanovic, R. 2013b. A multi-attribute decision making model based on distance from decision maker's preferences, Informatica 24(1): 103-118.

Stanujkic, D.; Zavadskas, E. K. 2015. A Modified Weighted Sum method based on the decisionmaker's preferred levels of performances, Studies in Informatics and Control 24(4): 461-469. https://doi.org/10.24846/v24i4y201510

Turskis, Z.; Zavadskas, E. K. 2010a. A new fuzzy additive ratio assessment method (ARAS-F). Case study: the analysis of fuzzy multiple criteria in order to select the logistic centers location, Transport 25(4): 423-432. https://doi.org/10.3846/transport.2010.52

Turskis, Z.; Zavadskas, E. K. 2010b. A novel method for multiple criteria analysis: grey additive ratio assessment (ARAS-G) method, Informatica 21(4): 597-610.

Wachowicz, T.; Błaszczyk, P. 2013. TOPSIS based approach to scoring negotiating offers in negotiation support systems, Group Decision and Negotiation 22(6): 1021-1050.

https://doi.org/10.1007/s10726-012-9299-1

Weitendorf, D. 1976. Beitrag zur Optimierung der räumlichen Struktur eines Gebäudes: Doctoral Dissertation, Weimar.

Zavadskas, E. K.; Turskis, Z. 2010. A new additive ratio assessment (ARAS) method in multicriteria decision making, Technological and Economic Development of Economy 16(2): 159-172. https://doi.org/10.3846/tede.2010.10 
Zavadskas, E. K.; Turskis, Z.; Kildiene, S. 2014a. State of art surveys of overviews on MCDM/ MADM methods, Technological and Economic Development of Economy 20(1): 165-179. https://doi.org/10.3846/20294913.2014.892037

Zavadskas, E. K; Antucheviciene, J.; Kalibatas, D.; Kalibatiene, D.; Nearly, A. 2017. Achieving nearly zero-energy buildings by applying a multi-attribute assessment, Energy and Buildings (in press). https://doi.org/10.1016/j.enbuild.2017.03.037

Dragisa STANUJKIC is a Full Professor of Information Technology and Decision Sciences at the Faculty of Management in Zajecar, John Naisbitt University Belgrade. He has received his MSc degree in Information Science and $\mathrm{PhD}$ in Organizational Sciences from the Faculty of Organizational Sciences, University of Belgrade. His current research is focused on decision-making theory, expert systems and intelligent decision support systems.

Edmundas Kazimieras ZAVADSKAS is Professor, Head of the Department of Construction Technology and Management at Vilnius Gediminas Technical University, Vilnius, Lithuania, and a chief researcher at Research Institute of Smart Building Technologies. He has a $\mathrm{PhD}$ in building structures (1973) and DrSc (1987) in building technology and management. He is a member of the Lithuanian and several foreign Academies of Sciences. He is Doctor Honoris Causa at Poznan, Saint-Petersburg, and Kiev universities. He is Editor-in-Chief and a member of editorial boards of a number of research journals. He is author and co-author of more than 500 papers and a number of monographs. His research interests include building technology and management, multi-criteria decision-making (MCDM) theory, automation in design and decision support systems.

Darjan KARABASEVIC is an Assistant Professor at the Faculty of Applied Management, Economics and Finance, University Business Academy in Novi Sad. He obtained his degrees at all the levels of studies (B.Sc. appl. in Economics, B.Sc. in Economics, Academic Specialization in the Management of Business Information Systems and $\mathrm{PhD}$ in Management and Business) at the Faculty of Management in Zajecar, John Naisbitt University Belgrade. His current research is focused on the human resource management, management and decision-making theory.

Zenonas TURSKIS. Prof. Dr of Technical Sciences, Chief Research Fellow at the Laboratory of Construction Technology and Management, Vilnius Gediminas Technical University. Research interests: building technology and management, decision-making theory, computer-aided automation in design, expert systems. He is the author of more than 110 research papers, which are referred in WoS database.

Violeta KERŠULIENĖ. Doctor, Assoc. Prof., Director of Legal Affairs at the Department of Law of Vilnius Gediminas Technical University, Lithuania. Author of 14 scientific papers. In 1991, she graduated from the Civil Engineering Faculty of Vilnius Gediminas Technical University and in 2008, she defended her doctoral thesis in the field of technological sciences. In 1999, she acquired the lawyer's qualification from the Faculty of Law of Vilnius University. Her research interests include decisionmaking, dispute resolution and decision support systems. 